overspill of work into home life; and role conflict. ${ }^{1}$ Indeed, the dynamics of a practice will alter as more women enter the profession as women are more likely to work part time than men. ${ }^{+}$Thus it is important that the impact of change is carefully monitored to avoid adverse impact on this profession. Ideally, a survey using both subjective and objective data is needed to determine the ongoing nature of these findings.

1 Karasek RA Jr. Job demands, job decision latitude and mental strain: implications for job re-design. Administrative Science Quartely 1979;24:285308.

2 Porter AMD, Howie JGR, Levinson A. Measurement of stress as it affects the work of the general practitioner. Family Pract 1985;2:136-46.

3 Morrell DC, Evans ME, Roland MO. The "five minute" consultation: effect of time constraint on clinical content and patient satisfaction. BMJ 1986;292: 870-3.

+ Cooper CL, Faragher B, Rout U. Mental health, job satisfaction, and job stress among general practitioners. BMF 1989;298:366-70.

Howie JGR, Porter AMD, Forbes JF. Quality and the use of time in general practice: widening the discussion. BMF 1989;298:1008-10

Myerson S. Under stress? Practitioner 1990;234:973-6.

7 Macpherson G. BMA sends the GP's' contract out for consultation. BMJ 1989;298:1406-7.

Morrell $D$. The new general practitioner contract: Is there an alternative? $B M J$ $1989 \cdot 298: 1005-7$.

9 Smith T. BMA rejects NHS review. BMf 1989;298:1405-6.
10 Scheiber SC. Stress in physicians. In: Payne R, Firth-Cozens J, eds. Stress in health professionals. Chichester: John Wiley, 1987:23-44.

11 Porter AMD, Howie JGR, Levinson A. Stress and the general practitioner. In: Pavne R, Firth-Cozens J, eds. Stress in health professionals. Chichester: John Wiley, 1987:45-70

12 Marsh G, Kaim Caudle P. Team care in general practice. London: Croom Helm, 1976

13 Van Sell M, Brief AP, Schuler RS. Role conflict and role ambiguity: integration of the literature and directions for future research. Human Relations 1981:34:43-71.

14 Selye H. Stress without distress. Philadelphia: Lippincott, 1979

15 Sutherland VJ, Cooper CL. Understanding stress: a psychological perspective for health professionals. London: Chapman and Hall, 1990:165-224

16 Crown S, Crisp AH. Manual of the Crown-Crisp experiential index. London: Hodder and Stoughton, 1979

17 Warr P, Cook J, Wall T. Scales for the measurement of some work attitudes and aspects of psychological well being. Fournal of Occupational Psycholog 1979;52:129-48.

18 a'Brook M. Psychosis and depression. Practitioner 1990;234:992-3.

19 Lloyd G. Alcoholic doctors can recover. BMF 1990;300:728-30.

20 French JRP, Caplan RD. Organisational stress and individual strain. In Marrow AJ, ed. The failure of success. New York: Amacon, 1973:30-66.

21 Grol R, Mokkink H, Smits A, Van Eijk J, Beck M, Mesker P, et al Work satisfaction of general practitioners and the quality of patient care. Fam Pract 1985;2:128-35.

22 Sales SM, House J. Job dissatisfaction as a possible risk factor in coronary hear disease. 7 Chronic Dis 1971:23:861-73.

23 Keeley D. Personal care or the polyclinic? BMJ 1991;302:1514-6.
This is the fourth in a series of articles dealing with aspects of managing change in general practice.

The Cairntoul Practice, Glasgow G14 0XT Mairi G B Scott, general practitioner

MSD Foundation, London E14 9WA

Marshall Marinker, director

BMf 1992;304: $1548-50$

\title{
Managing Change in Primary Care
}

\section{Imposed change in general practice}

\author{
Mairi G B Scott, Marshall Marinker
}

In the summer of 1989 the government published its intentions for the reform of the NHS, and for a new contract with general practitioners. Both the reforms and the contract were immediately subject to a host of detailed criticisms about content. But behind these criticisms there lay another - that the government was imposing the changes.

All change gives rise to two recriprocal anxieties. Abandoning established habits and arrangements and embracing new ones produce the anxiety of loss and the anxiety of the unfamiliar. In this article we are concerned not with the content of change but with its processes. Although we take as our starting point the concerns occasioned by the reforms of the NHS in the past three years, we do so in order to highlight the problems which can arise within each general practice when change is envisaged. These problems are magnified when there is a sense of imposition, of being the victim and not the agent of change.

This sense of imposition seems to relate to four factors: firstly, the degree to which the reasons for change seem to be arbitrary; secondly, the strength of the evidence of the need for change; thirdly, the degree to which the changes are expressed in terms of desired behaviours as opposed to desired outcomes; and, fourthly, the choice of strategies used to effect the change. We examine these factors in detail below.

\section{Reasons for change}

For the most part in general practice the reasons for change seem to be accidental. That is to say they seem to be a part of what may be described as the natural development of a practice. Even when they take place suddenly or unexpectedly they are accepted because the reasons are perceived to be inevitable - the product of human vagaries. There may be shifts in the local population, perhaps the proportion of elderly people has increased over the years; patterns of morbidity may change, sometimes abruptly; there may be staff related problems - partners quarrel, become ill, or resign; the practice may be invited to start vocational training; and

\section{Points to note}

- Change necessitated by circumstances is acceptable in general practice

- Change willed and enforced by others is considered arbitrary

- Often evidence is not available for required change

- Change based on fashion is less acceptable than that based on sound evidence

- Imposed change is more acceptable if it is expressed in terms of outcome rather than detailed behaviour

- The positive way to deal with imposed change is to create a sense of ownership of the change within the practice

so on. Such reasons for change may be burdensome but they will be perceived as accidental. They will certainly pose difficult problems but they will not be seen as having been arbitrarily imposed.

When change is perceived as having been willed by others rather than occasioned by need there is a sense of arbitrariness. The new contract, again, is the most obvious recent example. It was the sense that activities were willed as a matter of policy, politically decided and enforced by a monopolistic employer or commissioner, that caused the sense of helplessness and hopelessness.

It is not only governments that can engender these negative feelings. They can and often do arise within partnerships and group practices. A precedent partner arbitrarily decides to change his half day, or blocks the use of a deputising service, or persistently frustrates the wish of the others to employ additional staff. Change seems to be arbitrary when the initiator is strong and the evidence of need for change is weak.

\section{Evidence of the need for change}

It would be comforting if all the changes required in general practice were based on reliable evidence from 


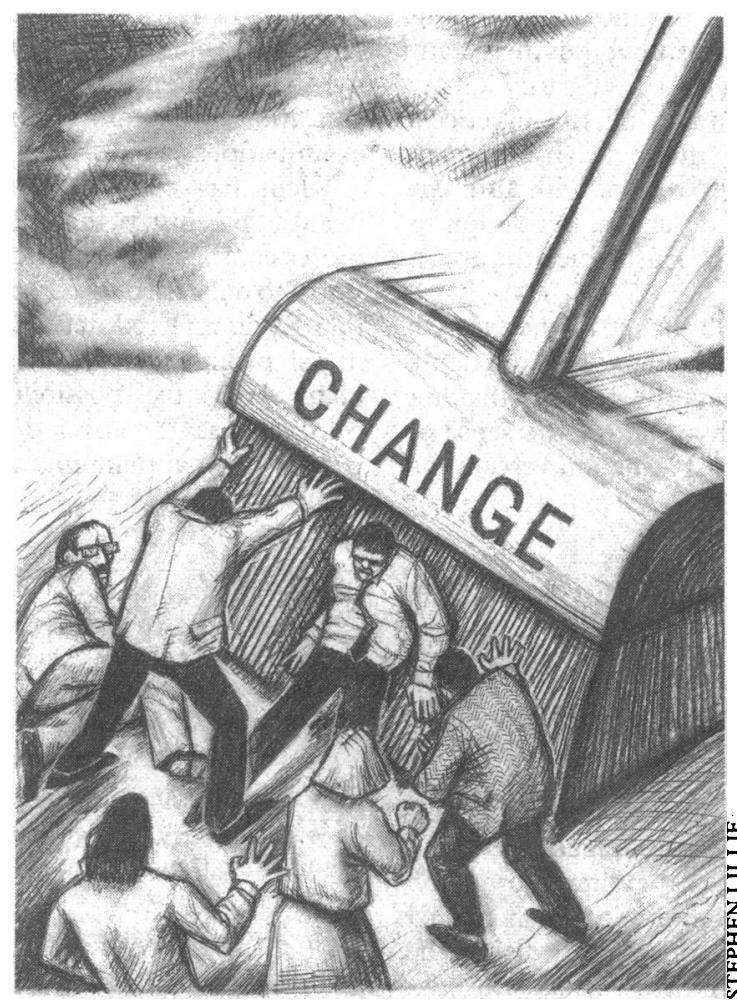

good empirical research. In the case of the new general practitioners' contract the evidence was either lacking or pointed in directions quite different from those proposed by the contract. ${ }^{1}$ Often, however, the evidence is simply not available, or is confused. We would argue, for example, that even in the absence of hard evidence counselling reduces morbidity or improves prognosis; counselling remains valuable because of what it says about the humane intentions of medical care. ${ }^{2}$ The practice of medicine cannot be driven by the evidence and rules of scientific inquiry alone. The doctor is not a clinical experimenter, but a healer. It is not only the provenance of change that is important but the openness with which that provenance is disclosed and discussed.

Change based on the vagaries of fashion is much less persuasive than change based on sound evidence. Fashion has played an important part in the development of twentieth century general practice. For the past 20 years primary care team work, educationalism (including role play and video consultation analysis), screening, health promotion, and performance review have all been fashionable. Although each of them has enhanced the character and complexity of modern British general practice, they were first and foremost fashions, with relatively short life spans. Most of them were driven by a small number of proselytising advocates (indeed one of us cannot be exonerated from much of this). In so far as the spread of the fashion has been experienced as growth and enlightenment, the changes were acceptable. But there remains the sense of being a slave to fashion. The violence of that term may explain much of the resentment and disdain expressed by general practitioners for the relatively innocent enthusiasms of academic bodies like the Royal College of General Practitioners.

\section{Processes and goals}

The creation of health promotion clinics, and in particular the introduction of protocols for these clinics, is an example of change not in the goals of care but in the detailed processes. To predict the activities of doctors' consultations as part of a contract is to rob them of their professionalism. It reduces the practice of medicine to a form of art which is no more creative or responsive than painting by numbers. This contrasts considerably with the implementation of change concerned not with processes but goals, as shown in the following example.

\section{EXAMPLE}

The practice has discovered that its appointment book has become increasingly filled, that patients are unable to see the doctor of their choice within a reasonable period of time, and the number of "extras" at each surgery grows from month to month. The change required is an improvement in the accessibility of the doctors.

Consider the number of possible options. It may be necessary to increase the number of consulting hours each week. This may entail the reallocation not only of time but also of space. The practice may have reached the point when an additional doctor or nurse should be introduced. The problem may be solved by creating fixed hours for telephone consultations. Inquiry may disclose that some doctors have very high recall rates, so that less than a third of their consulting slots are available for patients with new problems. The reasons for this can be explored and alternative solutions arrived at. In this example although the goal (better accessibility) may be imposed, the response is a professional one-it allows the professionals to propose solutions and to make choices. A sense of ownership is created.

\section{Strategies for effecting change \\ LEADERSHIP}

Whether the reasons for change are internal or external to the practice, whether the substance of the change seems to be imposed or not, change cannot be managed without leadership, and leadership is an uncomfortable concept in British general practice. The culture of general practice in this country is fiercely egalitarian. In part this is reflected in a continuing attachment to the independent contractor status within the NHS, even though the advantages of this may have diminished over the years. It is reflected in the model democracy of the BMA and the local medical committees. Within each individual practice partners today rapidly proceed to parity, not only parity of income with other partners who may have been in the practice for 20 years or more, but parity of workload and responsibility. Even when this is manifestly not the case there is a fierce attachment to the appearance of such equity. It is deeply unfashionable today to use the term "senior partner" without shyly indicating that quotation marks have been used.

Leadership in the practice may depend on several factors. There may indeed be a senior partner who exercises leadership on the basis of precedence or assumed authority. Leadership may be charismatic, a combination of enthusiasm, drive, and charm creating its own authority. Leadership may be appointed or delegated. A powerful partner or subgroup may cede power to one of their number. Sometimes the leadership is democratically elected by the group. Finally, leadership may be sapiential, deriving its authority from what it is that the doctor is believed to know and be capable of doing.

If the leadership is insecurely based, if it is only precedent, or charismatic or appointed, the freedom to act will be limited, and the trust of the group will be ungenerously given. If the leadership is more secure, if it represents the will of the majority or is seen to be justified by the competence of the individual, a more robust and creative leadership becomes possible.

Good leadership is the characteristic not of the individual but of the whole group. Without cooperation 
and consent the leader may produce a sparkling performance yet achieve next to nothing. It is important to remember that leadership is not necessarily a role, stable over time, and common to all the practice's endeavours. More commonly there is an elaborate dance of leadership between the partners, with different individuals assuming the role of leader, in relation to the task to be undertaken and the trust which the group is prepared to give.

When people are motivated to change by the exercise of threats and sanctions, by the calling in of old debts and the striking of new bargains, by rewards that are bribes and explanations which are bluff, the sense of ownership evaporates. Dishonest leadership creates its own sense of imposed change.

\section{COMMUNICATION}

It is a cliche of organisational theory, and of the sociological critique of doctors, that poor communication is the root of most management problems. But poor communication has a variety of causes. It is not simply a consequence of verbal incompetence or incontinence. Failures of communication may occur because of carelessness, conspiracy, or confusion. Most often we fail to communicate because we forget that information is power, and that giving information is empowerment. Failure to communicate can be part of a conspiracy. We fail to communicate or distort the message in order to hide our own mistakes or undeclared intentions. Lastly, and perhaps most commonly, failure to communicate results from confusion, when there seems to be no clear message to transmit. Of course in this situation nothing could be more useful than to communicate the confusion itself. This rarely happens because our medical education has taught us to hide our errors and conceal our ignorance.

\section{Coping with imposed change}

The positive response to imposed change is to create a sense of ownership of the change by the practice. It has been a common experience in the wake of the government's new contract that partners and practice teams have been forced to communicate with each other in a new and more helpful way, simply in order to survive the changes. This force majeure enhancement of general practice partnerships may be the most important (if unintended) benefit of the new contract. In response to the contract there has been widespread debate among general practitioners and within partnerships about the goals of good medical care, about what it is that would be worth achieving.

In an open society there is no unreasonable bureaucratic dictat that cannot be circumvented by intelligently misreading the rules. Practices and authorities can agree to aggregate so called health promotion consultations, so as to create fictional but paid health promotion "clinics." Course tutors will categorise courses to satisfy the idiosyncratic demands for different categories in order to qualify for the postgraduate education allowances. A programme concerned with diabetes mellitus can easily be classified as clinical medicine, or as practice management, or as prevention, without changes to its content.

\section{Conclusion}

This is the "age of contract." No matter what the political complexion of future governments, the NHS will henceforward be shaped by specific and detailed contracts. The professional staff of the NHS will be accountable for the fulfilment of these contracts, and the practice of medicine will in the future be determined by their content in exactly the same way as the education of doctors is now predicted by our college examinations.

Klein has commented that at the close of the twentieth century the relationship between all the professions and society is changing from one based on status to one based on contract. ${ }^{3}$ By "status" we believe that Klein referred not only to social authority but to moral authority and trust. The age of contract holds many attractive possibilities. Tightly constructed contracts may greatly reduce waste, boost efficiency, permit rational planning, and ensure public accountability.

\section{Contracts in the NHS: advantages and disadvantages}

- Contracts may reduce waste, improve efficiency, and enable national planning

- Contracts may devalue creativity

- There may be less emphasis on the needs of the individual patient and a preoccupation with group characteristics

- Strong contracts enfeeble professionalism

No planned health service can function without attention to the cost of services, to the calculation of cost benefit and opportunity cost, to performance indicators, explicit standards, compliance, conformity, controls, and accountability. These are the characteristics of the age of contract in medicine. They are the inevitable consequences of the growing demand for medical care, the growing success and cost of biotechnology, and the growing friction between desire and expectation on the one hand and financial constraint on the other.

But the age of contract also has its dangers. Too easily contracts can generate a repressive and controlling influence. Compliance can be valued above creativity. The power of numerate evidence from populations can be exaggerated. Medicine can become preoccupied with the characteristics of groups and become distracted from the assessment of, and response to, the needs of the individual. The personal, idiosyncratic, scientific, and moral dimensions of medical care can become subordinated to what authority arbitrarily deems to be the public good. Contracts may diminish the importance of the doctor's judgment about his or her unique patient in favour of predetermined choices - choices based on evidence of effectiveness and efficiency derived from studies of classes of patients and people. Strong contracts enfeeble professionalism.

Imposition is the unacceptable face of contract. Imposed change violates the professionalism of doctors which derives from the internalising of shared standards of technical and moral behaviour. Creating a sense of ownership of change is the only guarantee that the changes will work to produce real gains in the quality of care.

This series has been edited by Dr Mike Pringle.

1 Morrell DC. The role of research in development of organisation and structure of general practice. BMf 1991;302:1313-6.

Halmos P. The faith of the counsellors. London: Constable, 1965.

3 Klein R. From status to contract: the transformation of the British medical profession? In: Healthcare provision under financial restraint: a decade of change. profession? In: Healthcare provision under fin. 